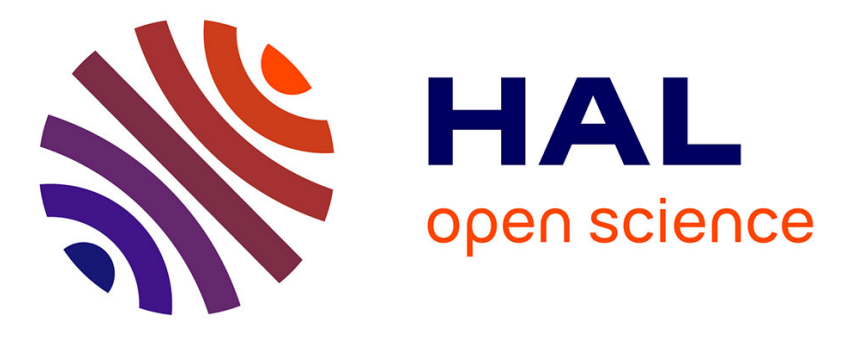

\title{
Stability Analysis of an Ultrasonic Motor for a New Wave Amplitude Control
}

Frédéric Giraud, Betty Lemaire-Semail, Julien Aragones, Jacques Robineau, Jean-Thierry Audren

\section{- To cite this version:}

Frédéric Giraud, Betty Lemaire-Semail, Julien Aragones, Jacques Robineau, Jean-Thierry Audren. Stability Analysis of an Ultrasonic Motor for a New Wave Amplitude Control. IEEE Transactions on Industry Applications, 2009, 45 (4), pp.1343-1350. 10.1109/07IAS.2007.73 . hal-01110762

\section{HAL Id: hal-01110762 https://hal.science/hal-01110762}

Submitted on 29 Jan 2015

HAL is a multi-disciplinary open access archive for the deposit and dissemination of scientific research documents, whether they are published or not. The documents may come from teaching and research institutions in France or abroad, or from public or private research centers.
L'archive ouverte pluridisciplinaire HAL, est destinée au dépôt et à la diffusion de documents scientifiques de niveau recherche, publiés ou non, émanant des établissements d'enseignement et de recherche français ou étrangers, des laboratoires publics ou privés. 


\title{
Stability Analysis of an Ultrasonic Motor for a new wave amplitude control
}

\author{
Frédéric Giraud, Betty Lemaire-Semail Laboratory of electrotechnics and power electronics of Lille \\ Avenue Paul Langevin \\ 59655 Villeneuve d'Ascq Cedex \\ Email: first name.name@polytech-Lille.fr Julien Aragones, Jacques Robineau \\ Jean-Thierry Audren SAGEM SA defence and security \\ Le Ponant de Paris \\ 27 rue Leblanc \\ 75512 Paris Cedex 15, France
}

\begin{abstract}
Using Piezo electric actuators can reduce the bulk size of servomechanisms; they are thus very useful in avionics applications. However, mechanical overload on the shaft of a Traveling Wave Ultrasonic Motor often results in the motor suddenly stalling. To avoid this drawback, one can increase the supply voltage or add a control loop in the rotating reference frame of the traveling wave. The consequences are extra power losses or lower dynamic performances.

The proposed method combines the advantages of classical controls and controls in a rotating frame: both stability and dynamic performances are obtained at low supply voltage levels. Experimental runs are presented.
\end{abstract}

\section{INTRODUCTION}

Traveling Wave Ultrasonic Motors (TWUM) exploit a piezoelectrically generated flexural wave which propagates at the surface of a stator. This wave is able to propel by contact a rotor strongly pressed on it. Friction produced by the contact mechanism is at the origin of numerous advantages, among which we can find: braking without supplying voltages, a high torque to mass ratio and high torque - low speed characteristics. Thus, while a speed reducer is often needed with an electromagnetic motor, it becomes useless in applications using TWUM: this leads to lightweight and compact applications. These features greatly increase the interest of these motors for servo applications in the avionics industry. Unfortunately, they are very difficult to control. First, since torque generation is non linear, it is difficult to precisely drive a load. However, solutions have been provided to solve that problem [1] and achieve precise position control in optoelectronic applications[2]. Secondly, the resonant behavior of the stator is very sensitive to different external conditions: temperature, load torque or mounting conditions. For example, the motor may stall if a mechanical overload is applied to the shaft, and this seriously decreases the reliability of servo mechanisms actuated by TWUM. Reducing the motor's sensitivity to external torque variations is thus a key issue for their use in avionic applications. In fact, bumps are typical of this kind of environment, where random disturbances are applied to the load and extremely accurate position or speed controls are needed. To solve this problem, one can increase the supply voltage. This displaces the torque limit which makes the motor stall, but does not remove the problem completely. Moreover, it increases the power losses and thus decreases the efficiency of the motor. Other solutions are proposed in [3][4]; [4] is based on a control of the motor in a rotating reference frame fixed to the traveling wave. By controlling the phase shift between the supply voltage and the traveling wave, it is possible to ensure operation for any load conditions. However, this solution slows down the traveling wave's dynamic. When implemented in a position control, this leads to lower dynamic performances compared to a classical frequency control. The aim of this article is to describe a new control method which helps to improve the reliability of the motor's operation at low supply voltage levels while maintaining good dynamic performances during transitory operations. For that purpose, an overview of method used to model these motors is given. Then the proposed control is detailed. Experimental results are given in the final section for an industrial optoelectronic application.

\section{MODELLING OVERVIEW}

\section{A. Modelling in the $\alpha \beta$ frame.}

A TWUM is made up of a ring shaped stator on which piezo-electric elements are bonded. If these elements are supplied close to the resonant frequency of this mechanical set, a bending wave is propagated in the stator. This travelling wave is able to propel by friction a rotor pressed on it (figure 1).

Different authors [5][6] have described the energy conversion process for TWUM. This process can be divided into three stages. In the first stage, the supply voltages named $v_{\alpha}$ and $v_{\beta}$ create forces via the inverse piezoelectric effect. In the second stage, the stator vibrates because of these forces. The deformation $w$ along the $\mathrm{z}$ axis can be written as 1

$$
w(\theta, t)=w_{\alpha}(t) \cos (\theta)+w_{\beta}(t) \sin (\theta)
$$

where the $w_{\alpha}$ and $w_{\beta}$ are the stationary wave's amplitudes, which occur if $v_{\alpha}$ and $v_{\beta}$ are supplied alone respectively, and $\mathrm{k}$ is the mode number. In figure 1 the stator is in contact with the rotor at one contact point along the wavelength. The wave crest location $\theta_{c}$ can be deduced from $w_{\alpha}$ and $w_{\beta}$ by [7]:

$$
k \theta_{c}=\tan ^{-1} \frac{w_{\beta}}{w_{\alpha}}
$$




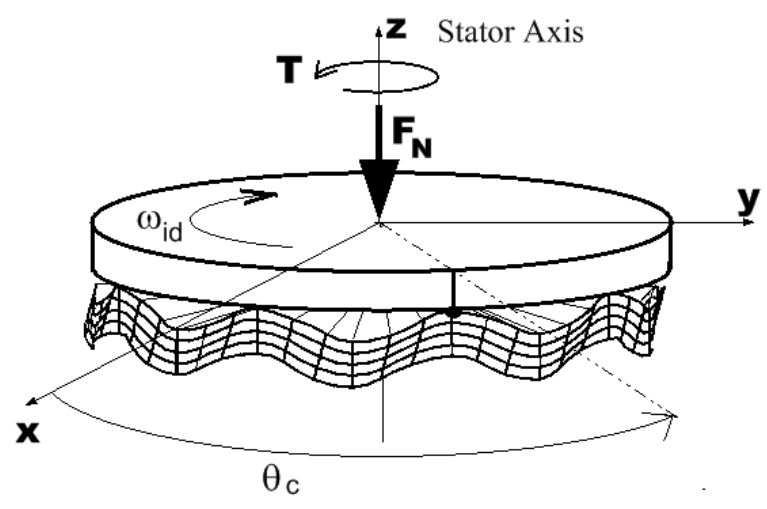

Fig. 1. Vibrating stator and the rotor pressed on it.

The relationship between $w_{\alpha}, w_{\beta}$ and $v_{\alpha}, v_{\beta}$ can be described using a $2^{\text {nd }}$ order equation

$$
\begin{aligned}
& m \ddot{w}_{\alpha}+d_{s} \dot{w}_{\alpha}+c w_{\alpha}=N v_{\alpha}-f_{r \alpha} \\
& m \ddot{w}_{\beta}+d_{s} \dot{w}_{\beta}+c w_{\beta}=N v_{\beta}-f_{r \beta}
\end{aligned}
$$

where $m, c, d_{s}$ and $N$ are parameters of the stator; [7]and [8] describe the protocol to identify these parameters. The resonant frequency of the stator is given by $\omega_{0}=\sqrt{\frac{c}{m}}$.

In equation $3, f_{r \alpha}$ and $f_{r \beta}$ take into account the external forces acting on the stator which are:

- the normal force pressing the rotor on the stator $F_{N}$

- the load torque $T$

Under the assumption of ideal contact (no sliding and conditions of ideal punctual contact), it is possible to deduce a relationship between $f_{r \alpha}, f_{r \beta}, F_{N}$, and $T$ :

$$
\left(\begin{array}{c}
f_{r \alpha} \\
f_{r \beta}
\end{array}\right)=R\left(k \theta_{c}\right)\left(\begin{array}{c}
F_{N} \\
k \frac{h}{b^{2}} T
\end{array}\right)
$$

where $h$ is the thickness of the stator and $b$ is the radius of the stator. $R\left(k \theta_{c}\right)$ is the well known rotational matrix, often used when modelling electromagnetic motors:

$$
R(\theta)=\left(\begin{array}{cc}
\cos (\theta) & -\sin (\theta) \\
\sin (\theta) & \cos (\theta)
\end{array}\right)
$$

The third stage of the energy conversion process is the friction between the stator and the rotor which produces the torque appearing on the shaft as a function of the wave's amplitude which is then the key variable controlling the motor.

\section{B. Complex phasors.}

It is quite common to use complex phasors in Electromagnetic machines with a rotating magnetic flux [9]; they are useful in obtaining simple representations of electrical variables ( voltage or current) of the machine at steady state conditions, and in finding their values. With complex phasors, we focus our attention on RMS or average values of the key variables.

In this section, we apply concept of complex phasors to TWUM. We attempt to construct a simple representation which will help to deduce the wave's amplitude as a function of the supply voltage's amplitude and frequency. Complex phasors rely on the concept of rotating reference frames. In fact, instant values of $w_{\alpha}$ and $w_{\beta}$ can be respectively deduced from the imaginary part and the real part of a complex number $\underline{w}$. And because $w_{\alpha}$ and $w_{\beta}$ are sinusoidal functions of time, the edge of $\underline{w}$ appears to rotate in the complex plane. The same is true for $v_{\alpha}$ and $v_{\beta}$ which can be deduced from $\underline{v}$. This concept of a rotating reference frame is summarized in figure 2 As such, we define the following complex variables:

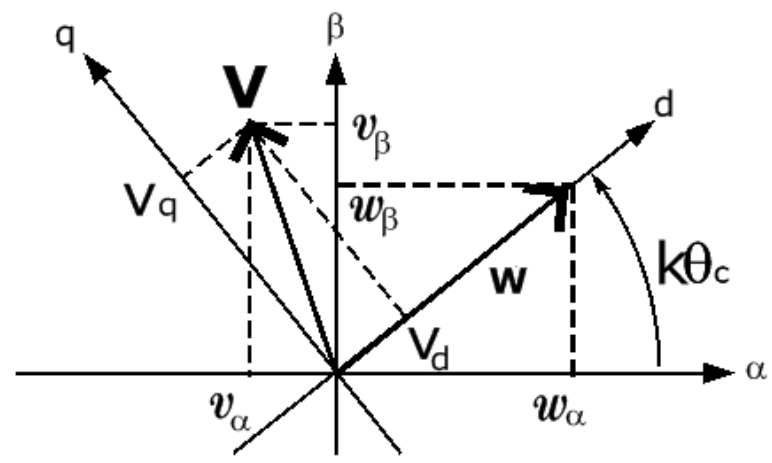

Fig. 2. Instant values of the stationary waves and voltages and the equivalent complex phasors $\underline{w}$ and $\underline{v}$.

$$
\begin{gathered}
\underline{w}=w_{\alpha}+j w_{\beta} \\
\underline{v}=v_{\alpha}+j v_{\beta}
\end{gathered}
$$

At this stage, we can deduce from 2 that:

$$
\underline{w}=\sqrt{w_{\alpha}^{2}+w_{\beta}^{2}} e^{j k \theta_{c}}
$$

and define

$$
W=\sqrt{w_{\alpha}^{2}+w_{\beta}^{2}}
$$

where $W$ is the wave's amplitude; 10 leads to:

$$
\underline{w}=W e^{j k \theta_{c}}
$$

Moreover, defining $\underline{f}_{r}$, and using 5 and 6 we can write:

$$
\underline{f}_{r}=f_{r \alpha}+j f_{r \beta}=\left(F_{N}+j k \frac{h}{b^{2}} T\right) e^{j k \theta_{c}}
$$

The relationship between the complex phasors presented in this section is deduced from 3 and 4 . In fact, $(3)+j \times(4)$ leads to:

$$
m \underline{\ddot{w}}+d_{s} \underline{\dot{w}}+c \underline{w}=N \underline{v}-\underline{f}_{r}
$$

To calculate the first and second derivatives of $\underline{w}$, we use 11 which gives:

$$
\underline{\dot{w}}=\frac{d}{d t}\left(W e^{j k \theta_{c}}\right)=\dot{W} e^{j k \theta_{c}}+j k \dot{\theta}_{c} W e^{j k \theta_{c}}
$$

When using complex phasors, we consider steady state only. Given this condition, $\dot{W}$ is obviously equal to 0 , since it is the amplitude of the wave in the stator. Moreover, for a perfect travelling wave propagating in the stator, the velocity of the contact point is given by the frequency $\omega$ of the two voltages, 
and we have $k \dot{\theta}_{c}=\omega ; \omega$ is supposed to be constant for steadystate operation. Finally, 14 can be revised to take into account the steady-state assumption:

$$
\underline{\dot{w}}=j \omega W e^{j \omega t}
$$

This gives

$$
\underline{\ddot{w}}=-\omega^{2} W e^{j \omega t}
$$

Using 12,15 and 16 to rewrite 13 gives

$\left(-m \omega^{2} W+j d_{s} \omega W+c W\right) e^{j} \omega t=N \underline{v}-\left(F_{N}+j k \frac{h}{b^{2}} T\right) e^{j \omega t}$

In order to simplify (17), we let

$$
\underline{v}=\left(V_{d}+j V_{q}\right) e^{j \omega t}
$$

We can see that $\sqrt{V_{d}^{2}+V_{q}^{2}}=V$, where $V$ is the voltage's amplitude. Finally, 17 can be rewritten as:

$-m \omega^{2} W+j d_{s} \omega W+c W=N\left(V_{d}+j V_{q}\right)-\left(F_{N}+j k \frac{h}{b^{2}} T\right)$

Equation (19) is of prime importance because it allows us to find the amplitude of the vibration of the stator, as a function of external conditions (load torque $T$ and normal preload $F_{N}$ ) and of the supply conditions ( $V$ and $\omega$ ). It can be divided into real and imaginary parts, leading to two new equations:

$$
\begin{gathered}
\left(c-m \omega^{2}\right) W=N V_{d}-F_{N} \\
d_{s} \omega W=N V_{q}-k \frac{h}{b^{2}} T
\end{gathered}
$$

This can be summarized as shown in figure 3 .

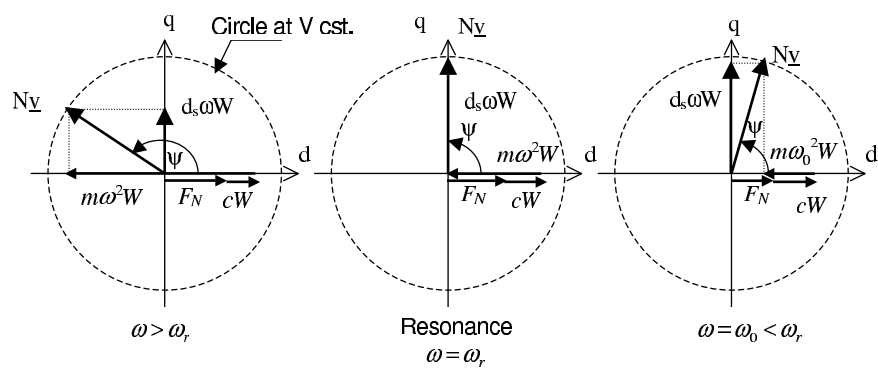

Fig. 3. Vector representation of steady-state operations in the rotating reference frame; $T=0$.

In this figure, the $d$-axis is the real axis, the $q$-axis is the imaginary one. Moreover, we assume that the amplitude of the supply voltages is constant, but the frequency varies. So the edge of underlinev moves along a circle of radius $V$.

Under no-load conditions $(T=0)$, and according to equation (21), $W$ can be deduced from the projection of phasor $\underline{v}$ on the $q$-axis, while $V_{d}$ satisfies (20). As $\omega$ approaches the resonant frequency of the motor, $V_{d}$ decreases and $V_{q}$ increases: $W$ thus increases. The maximum value for $W$ is thus attained if the phasor $\mathrm{V}$ is fully projected on the $q$-axis. For this operating point $V_{d}=0$.

If the motor is supplied below its resonant frequency, the motor stalls. This is well described in [4] and [10]. However, the stability of the motor under no-load conditions is not detailed in this article.
We can measure $\Psi$, the angle between $\underline{v}$ and $\underline{W}$. One can see that $\Psi$ decreases as the motor approaches resonance, reaching $\Psi=\frac{\pi}{2}$ for that point.

It is possible to measure $\Psi$ during experiments. In fact, as is the case for complex phasors, the angle measured in a complex plane is equivalent to a delay measured using a scope. In the case of TWUM, we have to measure the delay between the supply voltage $v_{\alpha}$ and $w_{\alpha}$ (or between $v_{\beta}$ and $w_{\beta}$ ). In this article, we give experimental results obtained with a Shinsei USR60 [11] A sensor is glued to the stator of the TWUM, which provides a voltage proportional to the stator's deformation which we call $v_{E A}$. Unfortunately, the sensor is not at the right place, and an additional delay of $254^{\circ}$ has to be taken into account between the sensor's voltage and $w_{\alpha}$.

Figure 4 shows values for $v_{\alpha}, v_{\beta}$ and $v_{E A}$ for steady state conditions, with $W=2 \mu \mathrm{m}$. A phase shift of $98^{\circ}$ is measured, leading to $\Psi=156^{\circ}$ when taking into account the location of the sensor. The corresponding complex phasors are depicted in figure 5 .

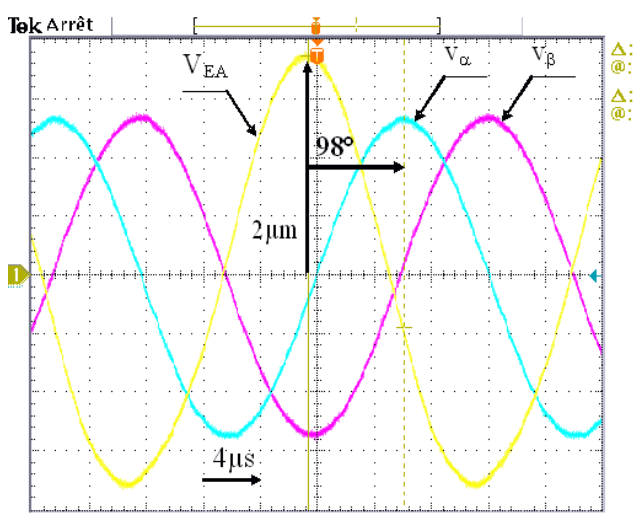

Fig. 4. Values of the motor's supply voltages and the output produced by the sensor for $W=2 \mu m$.

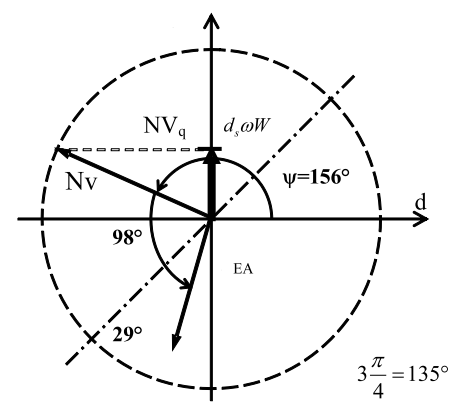

Fig. 5. Complex phasors for $W=2 \mu m$.

Figure 6 presents other values at $3 \mu \mathrm{m}$. We now measure a phase shift of $114^{\circ}$, which gives $\Psi=140^{\circ}$. These results are consistent with the analysis given in figure 3 , because $\Psi$ decreases as $W$ decreases. They show that complex phasors are useful to describe the motor's operating point. In the next section, we use them to analyze stability of the motor when we vary the external load torque. 


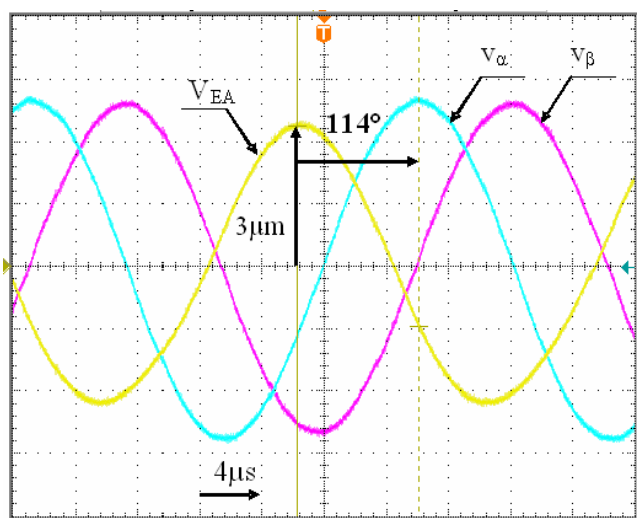

Fig. 6. Values of motor's supply voltages and the output produced by the sensor for $W=3 \mu m$.

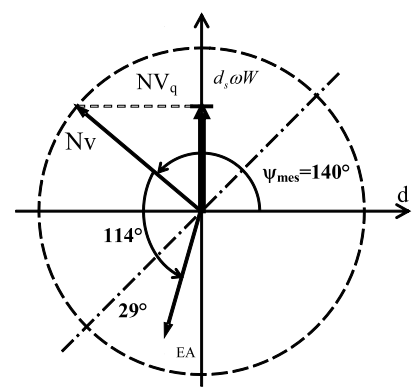

Fig. 7. Complex phasors for $W=3 \mu m$.

\section{STABILITY ANALYSIS AS A FUNCTION OF EXTERNAL LOAD TORQUE}

\section{A. Effect of a load torque}

If a load torque is applied on the shaft as depicted in figure $8, V_{q}$ - the projection of $\underline{\mathrm{v}}$ onto the $q$ - axis - is divided into two parts: one part for the wave propagation and one part for the load torque $T$. For a given wave amplitude $W$, if the load torque increases, then $\underline{v}$ gradually approaches the $q$-axis.

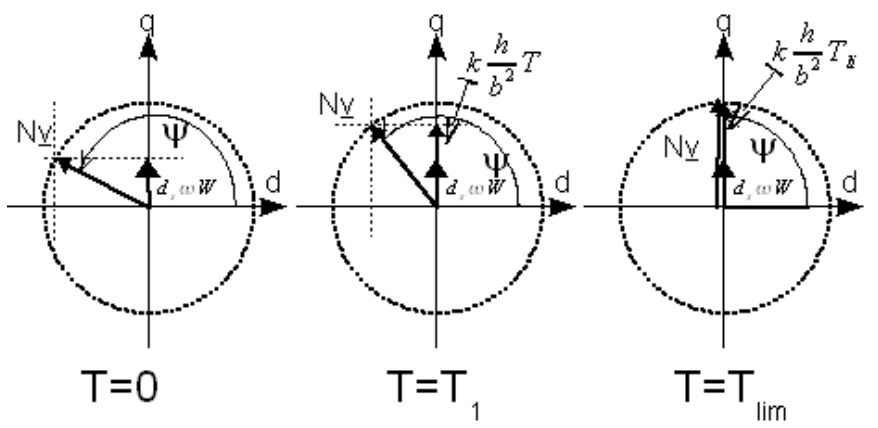

Fig. 8. Vector representation at resonance with two load torque values.

Once again, this can be experimentally verified as shown by the values in figure 9. For this run, $W$ is equal to $2 \mu \mathrm{m}$ as in figure 4, but now, an external load torque of $T=0.5 \mathrm{Nm}$ is applied to the shaft. As a consequence, the measured phase shift between $v_{E A}$ and $v_{\alpha}$ is equal to $120^{\circ}$, leading to $\Psi=$ $126^{\circ}: \underline{v}$ approaches the $q$-axis as $T$ increases.

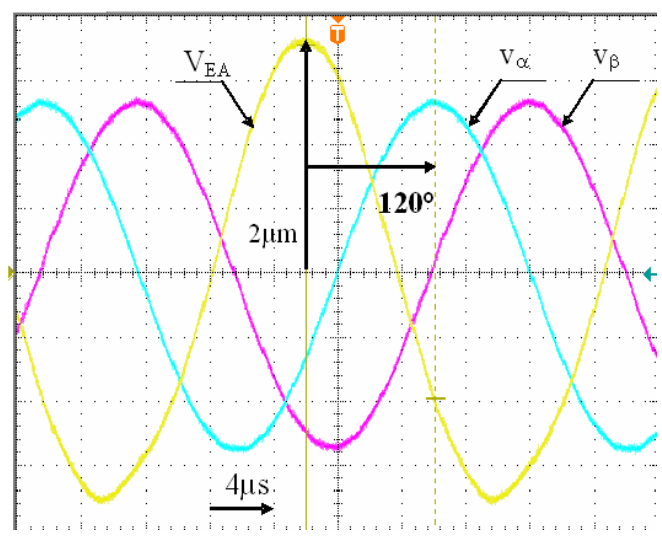

Fig. 9. Values for motor's supply voltages and the output produced by the sensor for $W=2 \mu \mathrm{m}$ and a load torque $T=0,5 \mathrm{Nm}$.

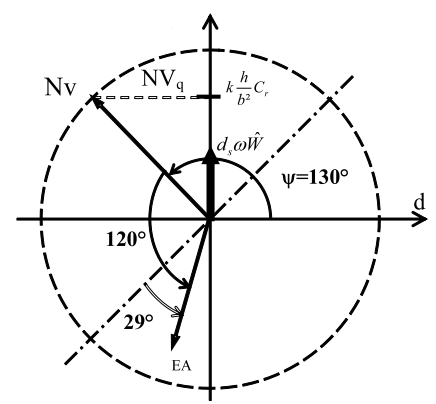

Fig. 10. Complex phasors for $W=2 \mu m$ and $T=0,5 N m$.

From figure 8, we can deduce that the maximum load torque which allows a stable operation of the motor is then given in the case when $\underline{v}$ is aligned on the $q$-axis. At this point, if $T$ becomes larger, the motor stalls, because it is not able to develop a higher torque: equation (21) has no solution. So, stable operations are ensured if

$$
\Psi<\frac{\pi}{2}
$$

is verifed.

\section{B. Safe operating area.}

The safe operating area of a TWUM is a zone delimited by three boundaries defined as follows:

- $W$ must be lower than a mechanical limit beyond which the bond layer would be destroyed. We call this limit $W_{\text {Max }}$,

- $T$ cannot be larger than a limit defined by tribological contact conditions between the stator and the rotor. We call this limit $T_{\text {Max }}$,

- The motor should not stall. This defines the maximum operating torque, called $T_{l i m}$.

$T_{\text {lim }}$ is a function of $V$ and $W$. In fact, starting from equation (21) we can deduce that the maximum available 
torque is given when $V_{q}=V$, leading to:

$$
k \frac{h}{b^{2}} T_{l i m}=N V-d_{s} \omega W
$$

In figure 11, we have drawn the boundary conditions of the safe operating area in the $(\mathrm{T}, \mathrm{W})$ plane, which seems to be more appropriate, for two values of the supply voltage $V(V 1>$ $V 2)$.

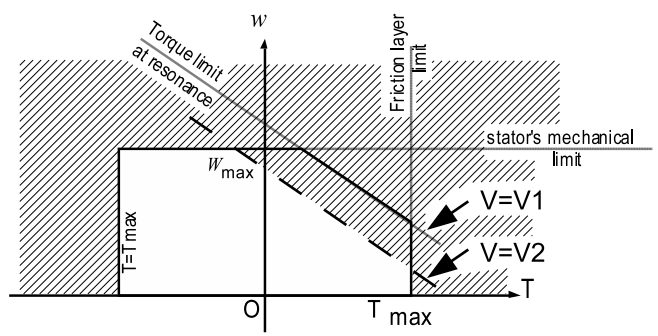

Fig. 11. Safe Operating Area for TWUM in the $(T, W)$ plane for $V=V 1$ and $V=V 2, V 1>V 2$

Figure 11 explains why, during operation, the motor may stall if extra load torque is applied to the shaft of the motor. The maximum load torque depends on the operating point itself: the bigger $W$ is, the less torque we have available. Moreover, we also understand why increasing the motor's voltage is a solution to the problem: in fact, this increases the maximum available torque for each travelling wave's amplitude. However, this solution is not effective because it leads to additional power losses in the motor and the production of heat.

\section{Experimental measurement of the safe operating area.}

It is possible to measure $T_{\text {lim }}$ as a function of $W$ and $V$. To do so, we increase the load torque on the shaft, by using a powder brake for example, and $\omega$ is adjusted so as to keep $W$ constant. During this test, we also measure the phase shift between $v_{\alpha}$ and $v_{E A}$, so as to estimate $\Psi$. All the variables were recorded. We noted the values of $T$ and $\Psi$ when the motor suddenly stalled ( $W$ failed to zero then) even though it was previously rotating normally. Runs depicted in figure 12

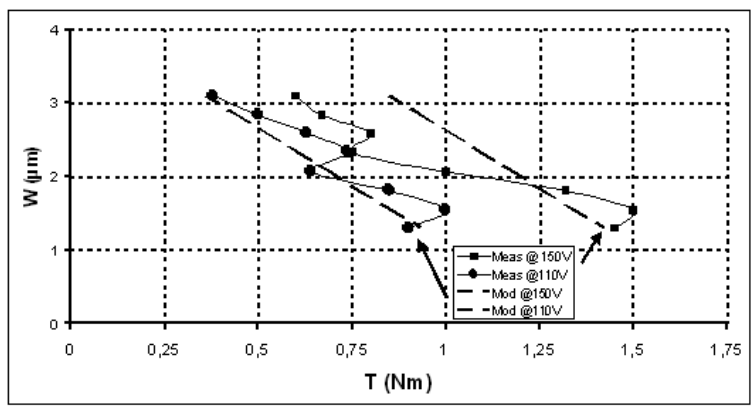

Fig. 12. Safe Operating Area for a Shinsei USR60 at $V=150 \mathrm{~V}$ and $V=110 \mathrm{~V}$

show that the maximum available torque $T_{l i m}$ actually depends on $W$ and $V$. However, we have found curves which are not equal to the modelling presented in this article. Of course, errors may be due to measurement errors of the load torque, or to the protocol (it is difficult to know exactly whether the motor has stalled or not). It may however be due to the modelling process which does not accurately take into account the specific contact conditions between the stator and the rotor.

Moreover, we do not verify in figure 13 that $\Psi=\frac{\pi}{2}$ when the motor stalls; at present, we cannot find a reason why such a difference occurs.

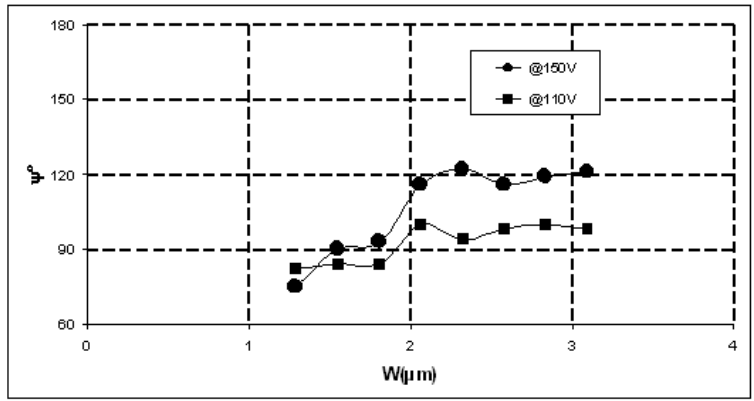

Fig. 13. Value of $\Psi$ when the motor stalls for $V=150 \mathrm{~V}$ and $V=110 \mathrm{~V}$.

However, because $\Psi$ can be easily measured for the motor, while we do not plan to measure the load torque in our application, keeping $\Psi>120^{\circ}$ seems to be a good solution to avoid the motor stalling at any voltage. This method will be exploited in a control detailed in the next section.

\section{WAVE AMPLITUDE CONTROLS OF TWUM.}

In TWUM, the key variable controlling the torque and the speed of the motor is $W$. This is why we should always find a Wave amplitude control loop in control schemes of TWUM. This section describes classical and new control strategies.

\section{A. Frequency control}

In classical controls, the frequency $\omega$ of the supply voltages is controlled so as to obtain a reference value of $W$, as shown in figure 14. This frequency control is straightforward, but is also very sensitive to the external conditions. In this control, $W$ is set independently of the load torque, and if a load larger than $T_{l i m}$ is applied, the motor stalls. To start up again, a long and specific procedure has to be followed: this closed loop control does not work in our case. In order to increase the torque limit, increasing $V$ is useful, but does not completely remove the problem. Moreover, it is difficult to precisely tune the loop controler, because the relationship between $W$ and $\omega$ is not linear. This control however is made up of a single loop, leading to excellent performances if we consider the response time obtained.

\section{B. Control in a rotating reference frame}

In addition to increasing the voltage, we could also adapt the reference value $W_{\text {ref }}$ shown in figure 14 when large load torques are applied to the shaft as described in figure 11: from the measurement of $T, \mathrm{~W}$ is adapted so as to ensure stable operation at resonance. 


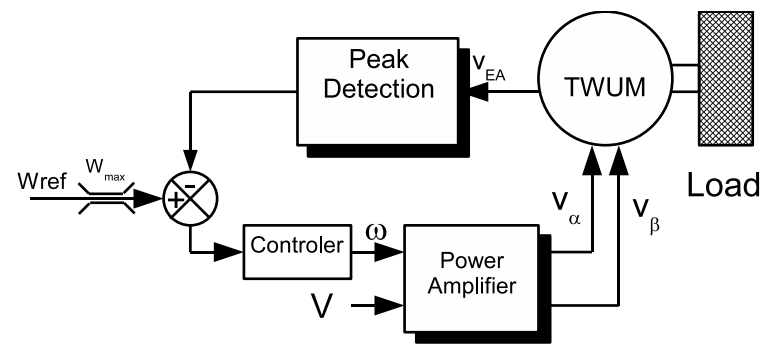

Fig. 14. Frequency control of a TWUM.

However, this solution is difficult since the measurement of $T$ requires space, extra weight and cost. This is why, instead of measuring $T$, it is better to measure $\Psi[4][12]$; stable operation of the TWUM above the resonant frequency will be ensured if (22) is verified. This is why [4] advises us to control $\Psi$ using an internal loop as shown in figure 15. This increases reliability, but at the expense of a time delay for the control of $W$ due to the internal loop of $\Psi$. This is why a hybrid control is proposed, which benefits from both control strategies.

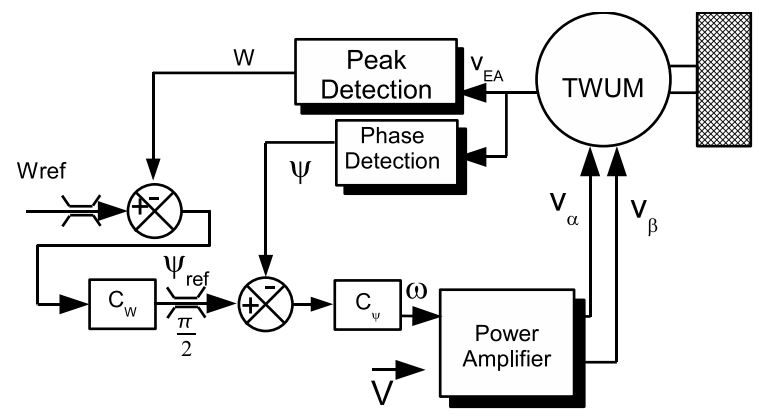

Fig. 15. Control in a rotating reference frame.

\section{Hybrid control strategy}

This control depicted in figure 16 uses two controllers running at the same time. One is using a frequency controller $C_{W}$ to control $W$ with respect to the reference value of $W_{\text {ref }}$. The other uses the controller in the rotating reference frame $C_{\Psi}$ to control $\Psi=\frac{\pi}{2}$. An additional strategy block switches from one controller to the other, depending on their output.

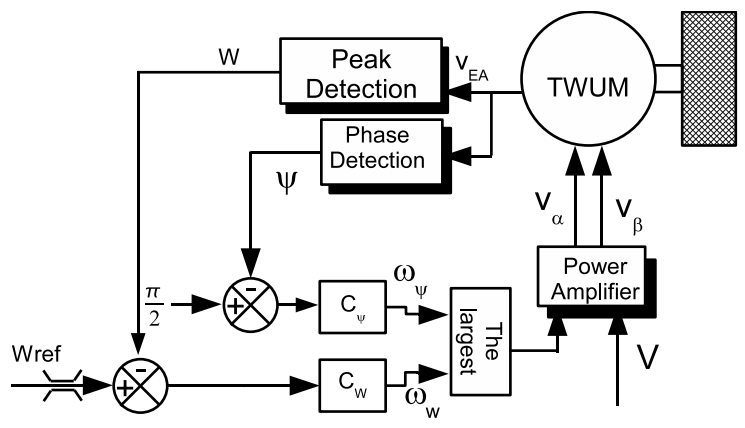

Fig. 16. Proposed strategy.
Under normal operating conditions, the motor is far from its resonance. So $\omega_{W}$ is larger than $\omega_{\Psi}$. The frequency of the motor is then controlled (point (1) in figure 17). If $T$ increases, $\Psi$ decreases because $V_{q}$ increases, as shown in section III. At point (2), $\omega_{W}=\omega_{\Psi}$ because $W=W r e f$ and $\Psi=\frac{\pi}{2}$. For a larger load torque, $W_{\text {ref }}$ cannot be obtained; the frequency controller fails to control $W$; in this mode $\omega_{W}<\omega_{\Psi}$, so $\Psi$ is controlled. Consequently, $W$ automatically adapts to the load torque: performances are diminished, but the motor does not stall.

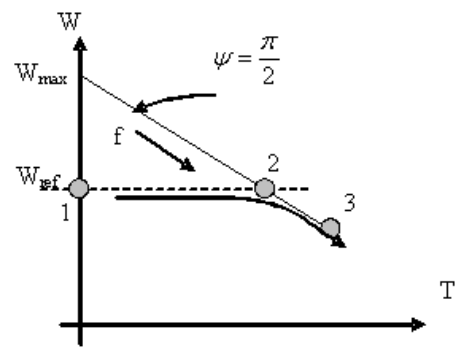

Fig. 17. W as a function of $T$ with hybrid control.

\section{Experimental runs}

The hybrid control was checked during experimental runs. The TWUM used is a Shinsei USR60, driven by a linear power amplifier. A specific electronic control was built and used for controlling the motor in its rotating reference frame; details can be found in[4]. An inertial load $\left(10^{-4} \mathrm{kgm}^{2}\right)$ is attached to the shaft along with a powder brake (figure 18). Moreover, the position of the motor is controlled as detailed in[13][2]. A response time of $200 \mathrm{~ms}$ and a position error of $1,3 \mathrm{mrad}$ - which is equivalent to $5000 \mathrm{dots} / \mathrm{rev}$ - are required. During the experiment, $\Psi_{r e f}$ is not equal to $\frac{\pi}{2}$ but $120^{\circ}$ as shown in section III. We use a Dspace 1104 board to implement the controller.

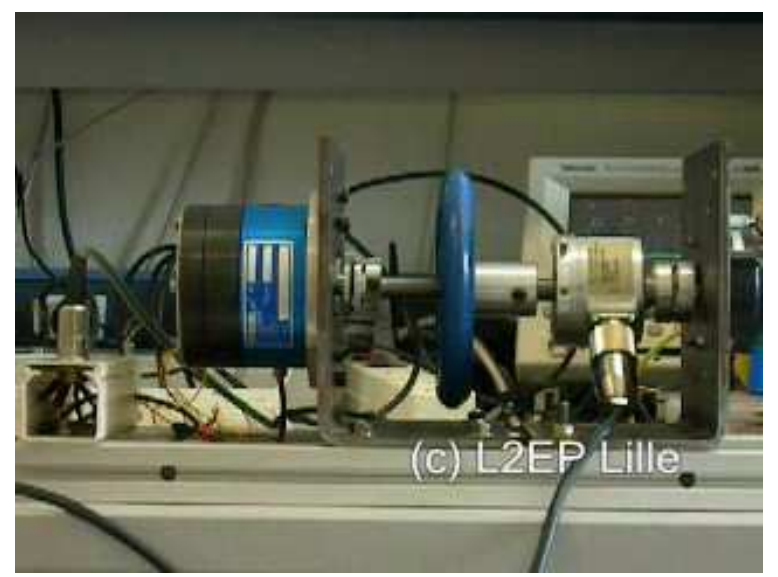

Fig. 18. The experimental test bench.

During the first run depicted in figure 19, the powder brake is off. Only load inertia is applying torque to the shaft. This is the normal operating mode: the measured value of $\Psi$ is 
larger than the reference, the frequency of the motor is fully controlled. For the second run of figure 20, an additional

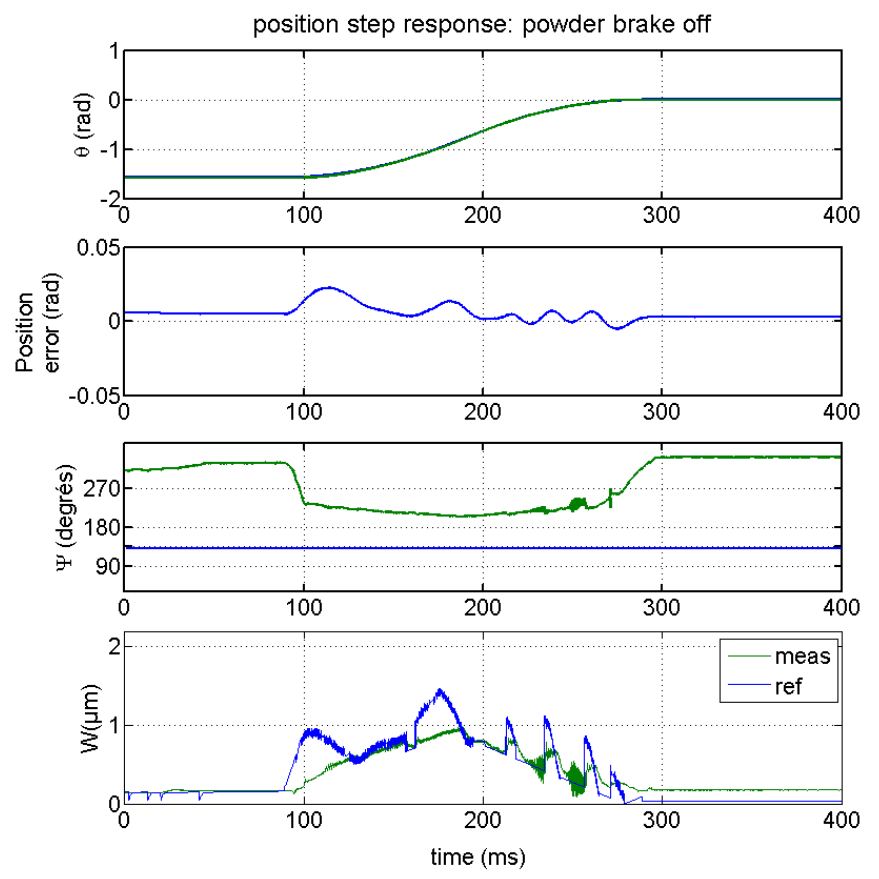

Fig. 19. Position step response when powder brake off @ $150 \mathrm{~V}$.

load torque is applied using the powder brake. Since this additional torque is too large, we should ensure that $W$ is smaller than its reference value in order to maintain stability. This is automatically achieved by using the proposed method. In fact, the motor operates close to its resonance, without stalling, and we thus obtain the best possible performances for this load condition. Of course, the response time is increased, but reliability is ensured.

\section{CONCLUSion}

In this paper, we present a novel control method which increases reliability of servo mechanisms using TWUM. This method is a hybrid control between a classical frequency control and a control in a rotating reference frame. Experimental results confirm performances at low supply voltage levels. Moreover, the strategy adopted is included in a position control loop.

\section{REFERENCES}

[1] T.Senjyu, T.Kashiwagi and K. Uezato, "Position control of ultrasonic motors using mrac and dead-zone compensation with fuzzy inference," IEEE Transactions on Power Electronics, vol. 17, pp. 265-2729, Mar. 2002.

[2] F.Giraud, B.Semail, J.Aragones, J.Robineau and J.-T.Audren, "Precise position control of a travelling wave ultrasonic motor," Proceeding of the 40th IAS annual meeting - Hong-Kong, vol. 3, pp. 1548-1554, Oct. 2005.

[3] J.Maas, T. Schulte, H.Grostollen, "Optimized drive control for inverterfed ultrasonic motors," IEEE Industry applications society ( IAS'97 ), vol. 1, pp. 690-698, Oct. 1997.
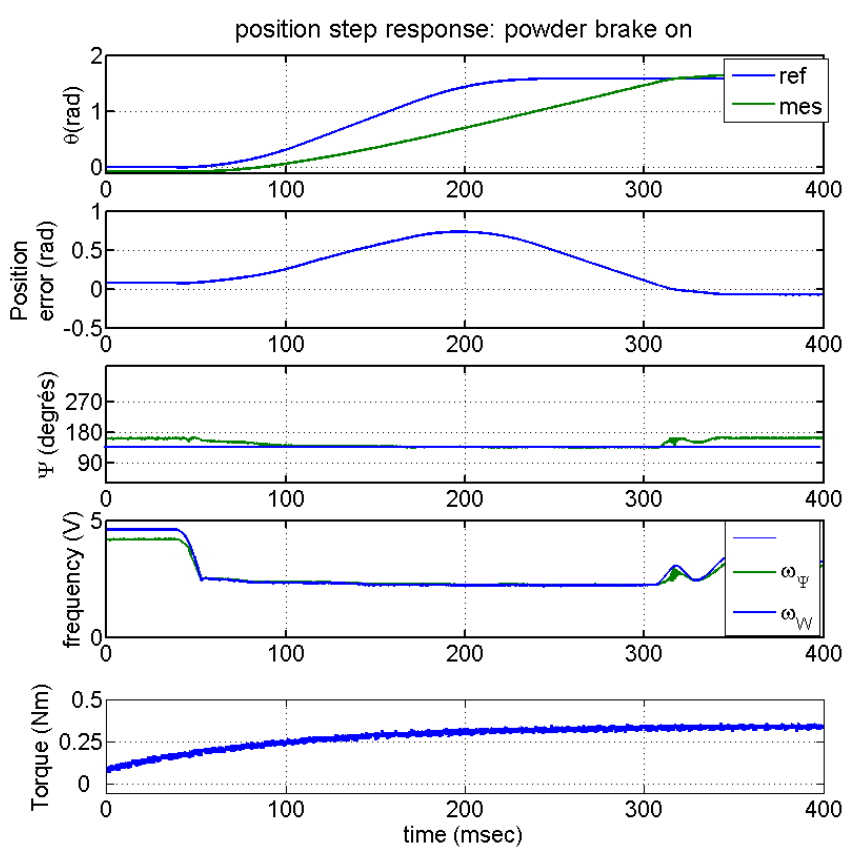

Fig. 20. Position step response when powder brake on @ 150V.

[4] F. Giraud, B. Semail, and J.-T. Audren, "Analysis and phase control of a piezo electric travelling wave ultrasonic motor for haptic stick application," IEEE trans. on Industry applications, vol. 40, pp. 15411549, nov-dec 2004.

[5] W. Hagood IV, A.J. McFarland, "Modeling of a piezoelectric rotary ultrasonic motor," IEEE Transactions on ultrasonics, ferroelectrics and frequency control, vol. 42, no. 2, Mar. 1995.

[6] N. E. ghouty, "Hybrid modeling of a traveling wave piezo electric motor," Ph.D. dissertation, Aalborg University, department of control engineering, May 2000.

[7] F.Giraud, B.Lemaire-Semail, "Causal modeling and identification of a traveling wave ultrasonic motor," The European Physical Journal of Applied Physics, no. 2, Feb. 2003.

[8] B.-S. F.Giraud, "A torque estimator for a traveling wave ultrasonic motor - application to an active claw," IEEE Transactions on Ultrasonics, Ferroelectrics and Frequency Control, vol. 53, pp. 1468-1477, Aug. 2006.

[9] P.Vas, Vector control of AC machines. Oxford Science Publications, 1990, iSBN 0-19-859370-8.

[10] J.Maas, T. Schulte, H.Grostollen, "Controlled ultrasonic motor for servodrive applications," 4th Eur. Conf. on smart structures and materials, 2nd Int. Conf. on micromechanics, intelligent materials and robotics ( MIMR'98 ), pp. 701-708, 1998.

[11] Shinsei corporation, "Internet website," http://www.shinsei-motor.com.

[12] M.Budinger, F.Giraud, B.Nogarède, J.-F. Rouchon, B.Lemaire-Semail, "Feeding and control electronic of a piezoelectric actuator," 8th Int. Conf. on new actuator ( ACTUATOR 98), pp. 363-366, Jun. 2002.

[13] F.Giraud, B.Semail, "Position control of a small travelling wave ultrasonic motor," Proceeding of the International Conference on New Actuators - ACTUATOR'2004, Jun. 2004. 


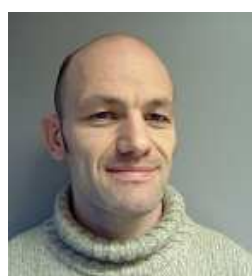

Frédéric Giraud was born in France in 1973. He is graduated from Ecole Normale Supérieure de Cachan, France in 1996 and received the B.S. degree in electrical engineering from Paris-XI University, Orsay, France in 1995, the M.S. Degree in electrical engineering in 1997 from Institut National Polytechnique de Toulouse, France, and the phD degree from Lille University, in 2002. He's a member of the electrical engineering and power electronics laboratory of Lille (L2EP) as an Associate Professeur. His research deals with the modelling and the control of standing wave and travelling wave piezo-electric actuators, for positioning and force feedback applications.

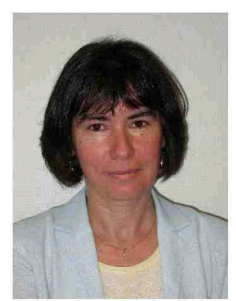

Betty Semail was born in France, in 1964. She received her Ph. D degree in 1990 from University of Paris XI, Orsay and habilitation degree in 1997 from University of science and technologies of Lille. She is now professor in university of Lille 1 . She is member of the electrical engineering and power electronics laboratory of Lille (L2EP) and responsible of the research axis upon control of electrical systems. She has been working motors and her main field of interest now deals with the modelling and control feedback applications.

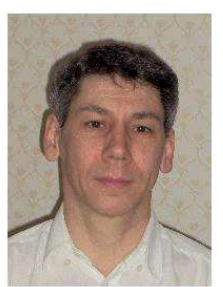

Jacques P. Robineau is gratuated of "Ecole Supérieure d'Electricité" (french top engineering school) in 1990 and achieved his PhD in electromagnetism. He has been working in electromagnetism numerical simulation (RF and optics) for 10 years, dealing with many aircraft and optronic laser stealth projects. He joined Sagem défense séecurité where he is in charge of advanced studies in airborne optronics.

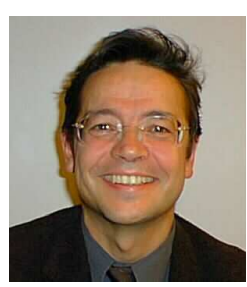

Jean-Thierry Audren was born in Paris, France on March 1st , 1951. He was graduated Engineer from Ecole Nationale Supérieure d'Electronique et d'Electromécanique de Caen in 1974. Since 1975 he has been in charge of RD in guidance, avionics and optronics systems. Since 1995 he has been leading research in the field of high power piezo motors in SAGEM. He is currently Deputy Director of the Air Land Warfare Business Unit of SAGEM, in charge of business Development.

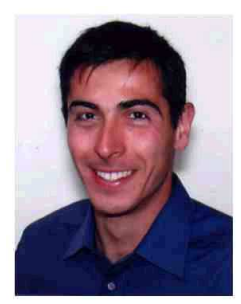

Julien Aragones was born in France in 1975, is graduated of University of Montpellier where he achived his $\mathrm{PhD}$ in automation and signal processing in 2002. He joined Sagem défense sécurité in 2003 where he works on helicopter sight heads. He is in charge of turret control for advanced studies in airborne optronic. 